\title{
De Suze a Suzy: as cocottes de António Patrício e Manoel de Oliveira
}

\author{
Paulo Alexandre Cardoso Pereira*
}

1. Integrado na coletânea Serão inquieto (1910) - incursão excêntrica e sem sequência de António Patrício no território do conto -, "Suze" foi já muito justamente considerado por David Mourão-Ferreira como "uma das indiscutíveis obrasprimas do conto português de todos os tempos" (1989, p. 76). Bem antes dele, um insuspeito Fernando Pessoa assegurava, em carta dirigida ao poeta espanhol Adriano del Valle, datada de 14 de setembro de 1923, que Serão inquieto era "um dos mais perfeitos livros de contos que se têm escrito em Portugal” (apud Lopes, 1993, p. 187).

De entre as cinco narrativas breves que compõem o volume - relatos de tonalidade filosófico-ensaística, uns; contos híbridos, de atmosfera ou de personagem, outros -, "Suze" terá decerto sido aquela que mais decisivamente contribuiu para a valoração póstera deste outro António Patrício, o contista bissexto de Serão inquieto. Isso mesmo se deduz, desde logo, da leitura de alguns testemunhos críticos coetâneos que, sem deixarem de enunciar certa reserva reticente, documentam a receção atenta de que foram objeto as imponderáveis narrativas de um poeta-dramaturgo. Em 1911, o psiquiatra e antropólogo criminal portuense Mendes Correia, num estudo intitulado $O$ genio e o talento na pathologia, recorria a algumas das personagens de Serão inquieto para substanciar, num exercício então frequente de clínica literária e sob a égide de Lombroso, vários diagnósticos de psicologia mórbida. A propósito da memorável cocotte de Patrício, argumentava o autor: "A Suze do Serão inquieto, essa deliciosa e transparente amante, cuja immoralidade leve e encantadora se reflecte na sua historia tão distintamente esquissada, é uma immoral lombrosiana, em que a arte do autor diluiu os traços biográficos" (CoRreiA, 1911, p. 24). No ano seguinte, Fialho de Almeida, censura, nos contos de Patrício, a composição esquemática e apressada de algumas figuras - Suze incluída - que, nas suas palavras, se aproximam de "fantoches, typos que desde

\footnotetext{
Doutor em Literatura Portuguesa e professor da Universidade de Aveiro, Aveiro, Portugal. Email: ppereira@ua.pt

1 Na impossibilidade de nela me demorar, omito aqui a recolha de fragmentos e aforismos à Heine ou Nietzsche que, sob o título hamletiano de "Words", surge apocrifamente atribuída a um putativo ex-consdiscípulo do autor, no que, como observa David Mourão-Ferreira, parece constituir o recurso a um álibi proto-heteronímico.
} 
o introito o contista arcabouçára para aguentar grandes papeis" ou ainda de "manequins postos em scena" (1912, p. 56-57).

Parto dos dois tropismos consignados por estas leituras críticas - o da doença e o do teatro - para revisitar, de forma necessariamente breve, o conto de António Patrício.

2. Esboçado no decurso do serão insone (e inquieto, como ominosamente antecipara o título da coletânea) de um anónimo narrador-amante (mas, ainda assim, um narrador sem máscara, estreitamente coimplicado com o autor, como salientou Mourão-Ferreira), "Suze" apresenta-se como um retrato delineado in fieri e de memória, conjeturalmente póstumo, da inolvidável cocotte com quem manteve uma relação breve e arrebatadora. Cadáver presuntivo e, portanto, ausente enquanto instância enunciadora em voz própria, o vívido fantasma de Suze ressurgirá, nesta erografia que se assume como tanatografia, por interposta palavra masculina, num exercício de cambiante impostação vocal:

Não posso dormir. Como há mais de oito dias não recebi carta de Suze, e a minha absurda vaidade se recusa a crer que ela me esqueça, ponhome a pensar, com uma perversidade triste, que tenho escrito loucuras a um cadáver. Na última contava ela com uma coragem simples, como o mais fútil incidente, que ia entrar prò hospital pra ser operada. [...] Se tivesse sido operada e convalescesse, já decerto me teria mandado um telegrama. É pois forçoso convencer-me de que a minha pobre Suze - "era uma vez”... Repito alto para mim mesmo: está morta, está morta a Suze! Logo que o disse alto, todo o meu temperamento de actor o acreditou, e em todo o meu ser, essa auto-sugestão ressoou em dobres, agudamente, por essa rapariga de vinte e três anos com quem vivi dois meses. A morta (é certo, é positivo que morreu) era alta e magra (PATRícıo, 2012, p. 73-74).

Se, desde a abertura do conto, se torna claro o regime dubitativo da efabulação - ou, mais rigorosamente, das elucubrações erráticas deste relator transtornado, que vacila entre a suposição e a certeza delirante -, essa mesma inconstância encontrará tradução na na indecidibilidade tipológica de um texto que, em falsa pista autorreferencial, se dá a ler como "última carta que te escrevo" (PAtrício, 2012, p. 84), mas que bem poderia antes ser página solta de diário, depoimento autobiográfico ou monólogo dramático. O confesso "temperamento de actor" (PATRício, 2012, p. 73) daquele que se entrega a este pungente trabalho rememorativo ajudará a explicar a volubilidade tonal do narrador que, no acanhado espaço enunciativo do conto, consegue mover-se entre a compunção contrita e a amarga autoironia,

\footnotetext{
2 Relembrem-se, a esse propósito, as seguintes palavras de David Mourão-Ferreira (1989, p. 78): "Mas há ainda que sublinhar a extrema coragem desse mesmo narrador que, ao longo de todo o conto, nem por um instante procura dissociar-se do autor aqui implícito e explícito, do indivíduo social que lhe serve de suporte - empenhando-se, pelo contrário, em fornecer todas as pistas que levem a confundi-los, a conjuntamente os responsabilizar, a recusar frontalmente, neste caso, quaisquer álibis de heteronímia”.
} 
a ternura melancólica e a raiva inconformada, num "proteísmo teatral" (PATRício, 2012, p. 82) que ele próprio reconhece em Suze, mas de que manifestamente compartilha. Armando Nascimento Rosa sublinhou a este propósito, muito acertadamente, a teatromania narrativa que habita alguns dos contos de Serão inquieto e de que se encontram abundantes vestígios em "Suze" (RosA, 2003, p. 137).

É, com efeito, no teatro que o narrador e a demi-mondaine primeiro cruzam olhares; Suze, de quem se diz emanar uma "estesia de actriz inconsciente" (PAtrício, 2012, p. 8o) é explicitamente comparada a atrizes (a Duse ou a Bernhardt) ou a heroínas trágicas, como a Desdémona shakespeareana. ${ }^{3} \mathrm{E}$ esta saturação de signos teatrológicos não deixa, por outro lado, de contaminar processualmente o sintagma narrativo, que integra ocasionais notações parentéticas, funcionalmente afins de didascálias - "(Mas assim não consigo dizer o que ela foi. Preciso calmar a minha febre e começar pelo começo)" (PAtrícıo, 2012, p. 74) - ou que reproduz, em interlúdio vaudevilesco, a canção do salgueiro de Aristide Bruant (PATRÍcıo, 2012, p. 76). Mais importante, o conto revela uma nítida tendência para o que poderia talvez designar-se como cenarização da memória. De facto, no seu desassossego rememorativo, este narrador parece bem menos empenhado na captação do passado como narrativa do que na imobilização cenográfica, compondo um tableau vivant dos tempos e dos lugares do idílio erótico a que a morte pôs termo. Suze é, por isso, fixada - encarcerada, diria o narrador - numa espécie de stasis, reminiscente da pose teatral:

Quando depois mais de perto a detalhei, achei-lhe um não sei quê de transido, de parado, espécie de caquemono, espécie de bebé enorme, enigmático, afltivo, como só um caricaturista-poeta criaria, num instante de emoção e febre, de quimera e riso! Pobre Suze! (PATrício, 2012, p. 76).

O rendimento temático e retórico da isotopia teatral conjuga-se, no conto, com um mais radical efeito de sobreteatralização, em consequência do qual vida e representação nele se indistinguem. Atriz premeditada de si própria, autoencenando-se num histrionismo que hoje se diria camp de máscaras sucessivas, em Suze parece renovar-se, em versão decadentista, a clássica metáfora do theatrum mundi. Não é já o mundo que se volve teatro - para Suze, que encena a vida como ato estético, nada existe para além do teatro:

Passa a teoria das nossas noites (em que os seus tiques profissionais me confrangiam) e ela era sempre de uma envolvência fluida, de uma estesia de actriz inconsciente, uma viciosa triste, insaciada, e uma boa e uma pobre rapariga. De começo podiam julgá-la artificial, tão estilizada era a

3 David Mourão-Ferreira salientou já como "este recorrente tema do teatro [se] articula [...] com o tema da prostituição, que envolve a denúncia da alienação, tão típica do mundo moderno, de que todos somos instrumentos e vítimas, e que se traduz também em 'fingimento' e em 'representação' de cada instante" (1989, p. 77). 
sua graça, tanto o seu requinte parecia consciente e erudito, traindo-se em tudo: no andar elástico, no dandismo sóbrio, e até no ruge-ruge da sua voz de alcova e confidência. Mas não: viam-na mal. Ela era assim sem esforço, naturalmente: ela nascera uma obra de arte (PATRício, 2012, p. 8o-81).

Neste universo do factício e do artificial, nada parece apartar o mundo real dos seus avatares de ficção. Por isso, Eça ou Fialho, segundo um "princípio de transposição ontológica" (REIS, 2015, p. 127) podem partilhar com Suze um mesmo palco que é o da vida-como-teatro:

Se Eça de Queirós fosse ainda vivo, eu que nunca o conheci, havia de apresentar-lhe Suze, e juro, que a acharia bem mais subtil, bem mais complexa e humanamente fascinante, que o seu extraordinário figurino - Carlos Fradique, dandy e epistológrafo. Fialho, mais feliz, pôde falar-lhe, viulhe gestos que valiam máximas, e ouviu-lhe memórias e anedotas bem mais significativas que parábolas. Mas por mais que insistentemente lho pedisse, nunca escreveu sobre ela: recusou-se (PATrícIo, 2012, p. 78).

3. Superando, pois, em afetada sofisticação, o "dandy e epistológrafo" Fradique, Suze é, como a personagem queirosiana, chamado a corporizar um script de género onde se intersetam a imaginação decadentista finissecular do feminino e a desfocagem operada por um olhar e uma dicção hegemonicamente masculinos. É certo que, intimada na sua fulgurante espectralidade, Suze monopoliza, nos planos referencial e simbólico-imaginário, todo o espaço do conto. Esta monomania diegética não encontra, contudo, paralelo no seu uso efetivo da palavra. Sumariamente condensada (e condenada) ao seu refrão emblemático - "Ça c'est un détail" (PATRícıo, 2012, p. 77) -, a um tempo blasé e filosófico, a pobre Suze é sobretudo aquela que obliquamente surge refratada pela consciência transfigurante e pela palavra facciosa do amante enlutado. Num estudo que se ocupa da representação do discurso da prostituta no romance francês do século XIX, Shoshana-Rose Marzel demonstra que, ao reproduzir a palavra da prostituta, o escritor exorciza, enunciando-os vicariamente, os seus próprios fantasmas (masculinos) de autolibertação. E conclui:

Dans ce cadre, le rapport de l'homme à la prostituée n'est pas un rapport à autrui, ni une reconnaissance de l'autre - mais un rapport à soimême. Le langage romanesque de la prostituée est donc spéculaire, et reflète l'homme tel qu'il aimerait se voir: sensuel, libéré, spontané, ludique, animal ou encore généreux et empathique (MARZEL, 2012, p. 9).

Duplamente fantasmática - porque presumivelmente morta e só rediviva graças à palavra reificante com que o homem que a amou tenta, em vão, "amortalhar o génio da Suze" (PAtrício, 2012, p. 78) -, na figura da demi-mondaine de Patrício congregam-se modelarmente as mitologias finisseculares do feminino perverso, já examinadas, em contexto português, por Paula Morão que, muito justamente, salienta que 
[...] se estes mitos correspondem a um modismo, está também por detrás deles uma questão cultural e de mentalidade: a concepção dos papéis que subjaz à misoginia, ao diabolismo e à femme fatale, frígida e impiedosa, insere-se num quadro de valores em que a ordem masculina impõe as suas leis, tolerando um mundo marginal cuja existência desconhece ou simula desconhecer (MorÃo, 2001, p. 38).

Ilustrando o erotismo mórbido que o figurino estético decadentista tinha colocado em voga ${ }^{4}$ - e entroncando, por essa via, numa linhagem de sensualidade perversa em que se incluía também a erotomania, o sadomasoquismo ou o fetichismo, desvios através dos quais "el cuerpo, en su totalidad erótica, se rebela contra todo lo que implica división en normas ou categorias" (LiTVAK, 1979, p. 86) -, na Suze de António Patrício tornam-se inteligíveis tanto atributos da femme fatale, hipersexualizada, poderosa e devoradora, ${ }^{5}$ como traços de um angelismo infantil, de uma elegância asténica e assexuada, reminiscente da femme fragile. ${ }^{6}$ A "cocotte nobilíssima" (PATRício, 2012, p. 78) é, em alternância contrapolar, figurada como "viciosa pálida" (PAtrício, 2012, p. 73), "criança escandinava” (PATrício, 2012, p. 74), "madona quatroccento" (PATrício, 2012, p. 74), "serpente-fantasma” (Patrício, 2012, p. 75), "serpentina bruxa" (PATRício, 2012, p. 75) ou "serafim profissional" (PATRício, 2012, p. 76), compondo uma etopeia ambivalente, consonante com um retrato, em chiaroscuro finissecular, de inocência perversa. Hesitante entre Salomé e Ofélia, vamp engimática e noiva de neve (LITVAK, 1979, p. 63), a lorette patriciana reedita o extenso rol dessas formas de erotismo "complicado e cerebral" (LiTvAK, 1979, p. 150) prescritas pela escatologia chic do fim-de-século e que aqui escolho ilustrar através do seu exuberante relato de voluptas mística:

- Tu sabes: não gosto de falar da minha vida. Nunca me queixei. Se agora te falo, é porque é pra dizer bem... Neste horror, tenho tido dias duma vo-

4 Como observa José Carlos Seabra Pereira, "ao prolongar a desmontagem queirosiana do erotismo burguês, [António Patrício] fá-lo menos em conformidade com o moralismo laico do NeoRomantismo vitalista e emancipalista, e fá-lo mais na sequência do cinismo cosmopolita instaurado pelo Decadentismo, remanescente em torno de uma mulher com tiques à Duse" (1995, p. 143-44).

5 Sobre o arquétipo finissecular da femme fatale, refere Lily Litvak: "La mujer es utilizada como uno de los símbolos más importantes; encarna la crueldad, la sensualidad perversa, la posesión del espíritu por el cuerpo. El demonio toma forma de mujer para seducir al hombre. Salomé, Dalila, Eva, Circe, Cleopatra, invaden la iconografía de la época. Es la seductora que atrae a su presa con sus largos y ondulantes cabellos. La mezcla de sadismo y sensualidad llegará a su máximo en la Salomé de Oscar Wilde, que Sarah Bernhardt habría representado en París, en 1891, de no haber sido prohibida" (1979, p. 3).

6 "El fin de siglo adoptó una figura de mujer como símbolo de inocencia y pureza, como ideal de amor espiritual y místico. El lejano modelo era Beatriz, que guía a su amado, de la mano, a través de las sombras, hacia una, más trascendente, realidad. En centenares de pinturas, marqueterías, porcelanas y poemas apareció la evocación de esa mujer de rostro pálido, delgada, ectoplásmica, blanca, desprovista de realidad. Era importante su mirada. Muchas de ellas se inspiraban en la Beata Beatrix de Dante Gabriel Rossetti, con los párpados caídos, la mirada introspectiva o perdida en el más allá" (LiTvaK, 1979, p. 63). 
lúpia imensa. Nem sei como te diga. Começo por me sentir doente, exasperada, sem poder mais... Eles vêm e eu penso que vou morrer de nojo. Vem um, vêm muitos... vêm todos... Então, não sei porquê, sinto um bemestar, um gozo doido; acho prazer a que me humilhem; parece-me que nasci para isto, que não há destino melhor... e gozo... gozo...

Depois, num riso seco:

- Sinto a volúpia dum cristão às feras...

Parou. Eu recebi num beijo o fumo do Laferme, e a Suze concluiu:

- Que importa isto! É um detalhe (PATRício, 2012, p. 82-83).

Como refere Lily Litvak no seu estudo sobre Erotismo fin de siglo, também aquí, o erotismo implica "profanación de lo divino, mancillamiento de lo bello, martírio de lo inocente. Se sigue la breve consigne de Sade: "Non hay voluptuosidad sin crime"” (LITVAK, 1979, p. 86).

4. Adaptado ao cinema, em 1998, pelo realizador Manoel de Oliveira, o conto "Suze" surge, no filme Inquietude, título de ressonância indisfarçavelmente patriciana, ${ }^{7}$ integrado num tríptico narrativo de que constitui a sequência intermédia. Não será difícil de compreender a sedução que sobre o realizador, com incursões assíduas no terreno da adaptação literária, ${ }^{8}$ terá exercido a narrativa de Serão inquieto. A intríseca teatralidade do conto de António Patrício não podia deixar de instigar criativamente Manoel de Oliveira, para quem,

O cinema não existe. Há apenas vida e teatro. De facto, a vida também não existe. $\mathrm{O}$ que há, verdadeiramente, é teatro. E não há vida porque acções da vida são de tal modo efémeras que o décimo de segundo que agora passou já não existe. É nesse sentido que digo que a vida não existe. A vida é toda cheia de convenções [...] o que regula e dá sentido à vida são as convenções. Portanto, que é que existe na vida? O teatro. [...] Mas o cinema, quer vá buscar à vida, quer vá buscar ao teatro, o que faz é uma representação. Não há distinção entre representação e vida (apud PRETO, 2008, p. 97).

7 Sobre a intenção que presidiu à escolha título do filme, refere Jacques Kermabon: "Il fallait pourtant un seul titre. Oliveira a choisi Inquiétude car, dit-il sans véritable conviction, 'il m'a semblé que, dans chaque histoire, il y avait plus ou moins quelque chose d'inquiétant'. En effet, ce film peut être une façon tripartite de montrer le désir latent chez les mortels d'atteindre à l'immortalité" (Kermabon, 1998, p. 38).

8 Como observa Nélson Araújo, "os textos literários são para Oliveira um filão de matéria fílmica usualmente utilizado por ele, e se muitos realizadores usam o texto como um ponto de referência ou como espaço de inspiração, para ele as obras são um elemento inviolável. Assim os filmes de Oliveira não rivalizam com os textos que estão na sua origem, pelo contrário, estes experimentam uma existência corpórea materializada pela fala dos actores. Esta fidelidade que o realizador mantém com a realidade literária inflaciona o valor da palavra na construção da sua imagem. Como afirma Rapfogel 'These are not adaptations of the source texts, but monuments to them"' (ARAújo, 2010, p. 56). 
Suze não enjeitaria subscrever esta desconcertante postulação do realizador de Inquietude $e^{9}$ a de que vida e representação se equivalem. A esta congenialidade performativa acresce o conhecido fascínio de Oliveira por esse dito eterno feminino que João Bénard da Costa mostrou já constituir a pedra de toque da sua obra cinematográfica, onde se deteta "um evidente desequilíbrio entre a força das mulheres e a fraqueza dos homens" (CosTA, 2001, p. 10). "O olhar sobre Inquietude" é, pois, acrescenta ainda Bénard da Costa (2001, p. 31), "um olhar feminino e o filme é, de novo, um filme sobre o mistério da mulher e a impotência masculina face a ela".

Mesmo subscrevendo esta leitura, vale a pena lembrar que a arquitetura cinematográfica engenhosamente concebida por Oliveira, e em função da qual o conto de Patrício, situado num plano diegeticamente transcendente, surge circundado por duas narrativas encaixadas que a ele sintaticamente se subordinam, não põe termo à hegemonia da perspetiva masculina. É certo que Suzy - sósia cinematográfica de Suze - assume agora, em resultado de um processo de transvocalização, a palavra que, no conto, lhe era sonegada pelo narrador masculino. Mas é, em larga medida, a partir do diálogo enquadrante mantido entre o narrador-diplomata e o seu amigo que, no filme, se opera a desenvolução da fábula cinematográfica, segundo o modelo do conto-dentro-do-conto. Do mesmo modo, por ter sido elidido o cenário de escrita insone em que se encontrava empenhado o narrador de $\mathrm{Pa}$ trício, esbate-se a dinâmica do telling retrospetivo do conto, substituído, no filme, pelo regime dramático do showing.

Manoel de Oliveira parte, assim, em Inquietude, da colagem improvável de três textos díspares: a peça de teatro em um ato Os imortais, de Prista Monteiro (1984), o conto de António Patrício e uma narrativa de Agustina Bessa-Luís, intitulada $A$ mãe de um rio (1981). A primeira, em estilo burlesco-filosófico, coloca em cena um pai que tenta induzir o filho ao suicído, convencendo-o de que preservar-se da indignidade da decrepitude é a única via de conquistar a imortalidade. No segundo, conta-se, em registo romântico-burguês, a trágica paixão de um dandy por uma cocotte, ambientando-a no cenário do Porto dos anos 1930. Por fim, o último relato, espécie de fábula mítico-folclórica, relata a história de Fisalina, jovem camponesa, do pacto feérico que estabelece com a mãe do rio, de quem vem a herdar o estigma sobrenatural dos dedos de ouro, e da sua posterior rejeição pelos habitantes da pequena aldeia onde vive. Embora ostensivamente se exiba a disparidade estilística, temática e mesmo cronológica das três histórias, elas surgem, no filme, habilmente concatenadas, sendo, portanto, reconduzíveis a uma linha diegética comum.

Assim, num artificioso dispositivo de teatro-dentro-do-cinema, a primeira história é apresentada como uma representação teatral, onde, depois de cair o pano, o dandy encontra Suze pela primeira vez. Será para confortá-lo pela morte da cocotte que um seu amigo lhe contará, na terceira secção do tríptico, o relato da mãe

\footnotetext{
9 Esta indistinção entre representação e vida explica que, nas palavras de Jacques Kermabon, "Inquiétude se déploie ainsi dans une sphère qui ne se réduit ni à une appartenance théâtrale, ni à la matière du monde quand bien même il emprunte à l'une et à l'autre" (KeRmaBon, 1998, p. 38).
} 
do rio. Como observa Jacques Parsi, "ce triptyque, fait de récits enchâssés, est tissé de nombreux jeux de renvois, de symétries et de rimes internes" (PARSI, 1998, p. 163), a começar pela presença circulante do feminino, personificado respetivamente em Marta, Suze e Fisalina que, ao terem direito à dignidade de um nome, contrastam com os homens anónimos que, em Inquietude, parecem apenas destinados a orbitar em torno delas.

Previsivelmente, esta sutura insólita, realizada por Manoel de Oliveira em Inquietude, impõe uma drástica ressemantização do conto de António Patrício. Suze encontra-se ainda com Suzy na consciência da sinistra cumplicidade que faz de thanatos o outro rosto de eros. O espectro da morte revela-se, aliás, ubíquo no filme. ${ }^{10}$ Mas é, talvez, pela insensatez que representa qualquer ambição de imortalidade que, mais coerentemente, se podem colocar em diálogo as três desconcertadas parábolas que compõem o filme. É certo que todas elas "possuem como tema central a impossibilidade do amor, mas também a incapacidade do homem de alcançar a imortalidade porque esta é a essência da mulher" (FERREIRA, 2004, p. 110): a sedutora Marta do primeiro quadro assombra pai e filho, sobrevivendo a ambos; Suze vampiriza a memória do amante, nela se eternizando; Fisalina, enfim, tornase a mãe do rio num tempo sem tempo (e, portanto, sem morte) que é o dos mitos. Por isso, ao apropriar-se da "grande frase, [d]a frase-medalhão, [d]a frase-refrém" (Patrício, 2013, p. 77) da Suze estóica de António Patrício - Tu sais, ça c’est un détail -, essa mesma que fazia dela "neta espiritual de Marco Aurélio" (PATrício, 2013, p. 78), a Suzy de Manoel de Oliveira parece nessa mesma frase verter o pessimismo niilista do Eclesiastes, como se antes dissesse "Vaidade das vaidades: tudo é vaidade". ${ }^{11}$

\section{Referências}

Araújo, Nélson Agostinho Marques. A arquitectura do plano oliveiriano. 2010. Tese (Mestrado em Estudos Artísticos) - Universidade do Porto, Faculdade de Belas Artes. 2010.

Correia, Antonio Augusto Esteves Mendes. O genio e o talento na pathologia. Porto: Imprensa Portugueza, 1911.

Costa, João Bénard da. Pedra de toque: o dito eterno feminino na obra de Manoel de Oliveira. Revista Camões, Lisboa, n. 12-13, p. 6-37, 2001.

\footnotetext{
10 "La mort est partout présente dans le film. Dès la première réplique: 'Tue-toi', que sur-dramatisent de tonitruants accords d'un concerto pour piano de Rachmaninov, la mort talonne les personnages. Et, qu'elle prenne le visage d'une double défenestration ou d'un corps, sans doute entaillé, sur une froide table d'opération, elle est brutale, elle est violente" (PARSI, 1998, p. 164).

"1 "La vie, nous explique Suzy dans le motif central, 'n'est qu'un détail'. Dans ses propos, ce leitmotiv sonne comme le 'tout n'est que vanité' de l'Ecclésiaste" (Kermabon, 1998, p. 39).
} 
Ferreira, Carolin Overhoff. Entre a transgressão e a afirmação da Lei do Pai: algumas protagonistas do cinema português nos anos noventa. In: Toscano, Ana Maria da Costa; Godsland, Shelly (Org.). Mulheres más: percepção e representações da mulher transgressora no mundo luso-hispánico. Porto: Universidade Fernando Pessoa, 2004, p. 103-120.

InQUIETUDE. Realização: Manoel de Oliveira. Intérpretes: Isabel Ruth, José Pinto, Leonor Silveira, Luís Miguel Cintra et al. Portugal/França/Espanha/Suíça: Madragoa Filmes, 1998. DVD.

Kermabon, Jacques. Le petit théâtre d'Oliveira. Cinéma et Engagement, Paris, v. 2, n. 93-94, p. 38-39, outono 1998.

LitvaK, Lily. Erotismo fin de siglo. Barcelona: Antoni Bosch, 1979.

Lopes, Teresa Rita. Pessoa inédito. Lisboa: Horizonte, 1993.

MArzel, Shoshana-Rose. Le langage de la prostituée dans le roman du dixneuvième siècle. In: Actes du Congrès Le XIXe siècle et ses langues. Société des Etudes Romantiques et Dix-neuvièmistes (SERD). Paris, p. 1-10, 2012. Disponível em: http://etudes-romantiques.ish-lyon.cnrs.fr/wa_files/Langues-Marzel.pdf. Acesso em: 9 jan. 2018.

Morão, Paula. Salomé e outros mitos. O feminino perverso em poetas portugueses entre o fim-de-século e Orpheu. Lisboa: Cosmos, 2001.

Mourão-Ferreira, David. António Patrício: da época à obra. In: MourãoFERreIra, David. Sob o mesmo tecto. Estudos sobre autores de língua portuguesa. Lisboa: Presença, 1989. p. 59-78.

PARSI, Jacques. Inquiétude. L'art du cinéma (Manoel de Oliveira), Paris, n. 21-22-23, p. 162-168, outono 1998.

Patrício, António. Serão inquieto. Lisboa: Assírio \& Alvim, 2012.

Pereira, José Carlos Seabra. António Patrício - Entre a emoção e a ironia. Máthesis, Viseu, v. 4, p. 117-148, 1995.

Preto, António. Manoel de Oliveira: o cinema inventado à letra. Porto: Fundação de Serralves, 2008.

ReIs, Carlos. Pessoas de livro. Estudos sobre a personagem. Coimbra: Imprensa da Universidade de Coimbra, 2015.

RosA, Armando Nascimento. As máscaras nigromantes. Uma leitura do teatro escrito de António Patrício. Lisboa: Assírio \& Alvim, 2003.

Recebido em 28 de maio de 2018.

Aprovado em 17 de setembro de 2018. 


\section{Resumo/Abstract/Resumen}

\section{De Suze a Suzy: as cocottes de António Patrício e Manoel de Oliveira}

\section{Paulo Alexandre Cardoso Pereira}

Integrado na coletânea Serão inquieto (1910), de António Patrício, o conto "Suze" tem sido unanimemente considerado como uma obra-prima do género. Neste artigo, são, num primeiro momento, examinadas as estratégias de composição do retrato da cocotte, protagonista do conto, correlacionando-as com a mitologia contrapolar do feminino que a literatura finissecular ajudou a difundir. De seguida, propõe-se o confronto da narrativa de Patrício com a sua adaptação cinematográfica por Manoel de Oliveira que, no filme Inquietude (1998), o converte numa das histórias de um tríptico narrativo. Apesar do que manifestamente as afasta, nas cocottes de Patrício e de Oliveira torna-se ostensiva uma idêntica pulsão de autoencenação que se traduz numa contaminação dramática tanto do conto, como do filme.

Palavras-chave: conto, António Patrício, Manoel de Oliveira, cocotte, Decadentismo, teatralidade.

From Suze to Suzy: thecocotte according to António Patrício and Manoel de Oliveira

\section{Paulo Alexandre Cardoso Pereira}

Included in the collection Serão inquieto (1910) by António Patrício, "Suze" has been repeatedly hailed as a masterpiece of the short story genre. In this article, we start by discussing the strategies of composition used in the portrayal of the cocotte who is the protagonist of the short story, examining them in the light of the fin-de-siècle conflicting mythologies of the feminine. We then seek to compare the portrait sketched in Patrício's narrative with its adaptation to the cinema carried out by Manoel de Oliveira. In his 1998 film, Inquietude, the Portuguese director reshapes the literary narrative, converting it into one of the stories embedded in a triptych. Regardless of what manifestly sets them apart, Patrício and Oliveira's cocottes share a common self-staging instinct which ultimately leads to the dramatic contamination of both short story and film.

Keywords: short story, António Patrício, Manoel de Oliveira, cocotte, Decadence, theatricality

De Suze a Suzy: las cocottes de António Patrício y Manoel de Oliveira

\section{Paulo Alexandre Cardoso Pereira}


Incluida en la colección Vigilia Inquieta (1910), de António Patrício, la novela corta "Suze" ha sido unánimemente considerada como una obra maestra del género. En este artículo, en un primer momento, se examinan las estrategias de composición del retrato de la protagonista, correlacionándolas con la mitología antagónica de lo femenino que la literatura finisecular ayudó a difundir. A continuación, se confronta la narrativa breve de Patrício con su adaptación cinematográfica por Manoel de Oliveira quien, en su película de 1998, Inquietud, la convierte en una de las historias de un tríptico narrativo. A pesar de lo que las aleja, en las cocottes de Patrício y de Oliveira se observa una idéntica pulsión de auto-escenificación que se traduce en una contaminación dramática de la novela corta y de la película.

Palabras clave: novela corta, António Patrício, Manoel de Oliveira, cocotte, Decadentismo, teatralidad. 